\section{Case Reports in Ophthalmology}

\title{
Sturge-Weber Syndrome Associated with Monolateral Ocular Melanocytosis, Iris Mammillations, and Diffuse Choroidal Haemangioma
}

\author{
Andrea Maria Plateroti ${ }^{\mathrm{a}}$ Rocco Plateroti ${ }^{\mathrm{a}}$ Roberto Mollo ${ }^{\mathrm{a}}$ \\ Aloisa Librando $^{a} \quad$ Maria Teresa Contestabile $^{b}$ Vito Fenicia $^{b}$ \\ a Ophthalmology Unit, DAI Head and Neck, Azienda Ospedaliera Universitaria Policlinico

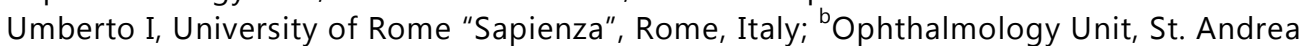 \\ Hospital, NESMOS Department, University of Rome "Sapienza", Rome, Italy
}

\section{Keywords}

Sturge-Weber syndrome - Ocular melanocytosis · Glaucoma · Choroidal haemangioma . Iris mammillations $\cdot$ Phacomatosis pigmentovascularis

\begin{abstract}
We present the case of a 12-year-old boy with Sturge-Weber syndrome and ocular melanocytosis who presented with bilateral naevus flammeus of the face and hyperpigmentation of the right iris associated with ipsilateral iris mammillations. The patient had glaucoma and a diffuse choroidal haemangioma of the right eye. Optical coherence tomography of the anterior segment confirmed iris hyper-pigmentation and did not show abnormalities of the chamber angle structures. B-scan ultrasonography and enhanced depth imaging optical coherence tomography were performed and showed a marked difference in thickness and reflectance between the right and left choroid. Visual field examinations with perimetry showed early defects in the right eye. Peripapillary optical coherence imaging showed borderline values of retinal nerve fibre layer thickness reduction in the right eye. Sturge-Weber syndrome associated with ocular melanocytosis and iris mammillations is an extremely rare condition. This paper highlights the role of multi-imaging methods in the enhanced evaluation of rare diseases towards choosing the most appropriate management strategies and improving the follow-up of patients over time.




\section{Case Reports in Ophthalmology}

\section{Introduction}

Sturge-Weber syndrome (SWS), also known as encephalo-trigeminal angiomatosis, in its complete form includes the classic triad of naevus flammeus of the face, ipsilateral leptomeningeal angiomatosis, and ocular involvement $[1,2]$. The Roach classification distinguishes SWS into classic or type I presenting facial and leptomeningeal haemangioma with or without glaucoma, type II with facial haemangioma with or without glaucoma, and type III with leptomeningeal haemangioma only [3]. The facial naevus flammeus can involve the eyelids and conjunctiva, but the most common ocular manifestation of the disease is glaucoma ipsilateral to the naevus flammeus occurring in $50-70 \%$ of patients $[4,5]$. In about $53 \%$ of cases choroidal thickening is reported due to diffuse haemangioma, which is observed on ophthalmoscopic examination as a diffuse red-orange dark colour of the fundus with respect to the contralateral eye colour [6-8].

Rarely, SWS can be associated with oculodermal melanocytosis $[9,10]$. This condition presents with excessive melanocytes in the peripheral ocular skin and various ocular areas including the uvea and sclera $[11,12]$. It rarely occurs in Caucasian patients, being more frequent in Asian ethnicity [13]. Infrequent manifestations in oculodermal melanocytosis are iris mammillations, which are unilateral iris protuberances with an even distribution on the iris $[14,15]$. Patients presenting both cutaneous naevus flammeus and pigmentary naevi have been classified with phacomatosis pigmentovascularis [16, 17].

In the present paper we report on a rare case of SWS in a young patient with bilateral naevus flammeus, monolateral iris heterochromia due to ocular melanocytosis associated with ipsilateral iris mammillations, glaucoma, and choroidal haemangioma.

\section{Case Report}

A 12-year-old boy presented to our ophthalmology unit due to a facial angioma involving the right side of the face. Magnetic resonance imaging was negative for leptomeningeal haemangioma. At presentation to our unit we observed a naevus flammeus, involving the course of the ophthalmic and maxillary branches of the 5th cranial nerve, on both sides of the face with more extensive involvement of the right side. Best corrected visual acuity was $20 / 20$ in both eyes. Slit lamp examination showed iris heterochromia due to hyperpigmentation of the right iris associated with ipsilateral iris mammillations (Fig. 1). Intraocular pressure measured with Icare tonometry was 22 and $12 \mathrm{~mm} \mathrm{Hg}$ in the right and left eye, respectively [18]. Gonioscopy showed that the angle was open in both eyes but there was diffuse hyperpigmentation of the angle in the right eye. Optical coherence tomography (OCT) (Optovue, Fremont, CA, USA) of the anterior segment revealed an increase in reflectance of the iris surface in the right eye (Fig. 2). Ophthalmoscopic fundus examination showed an increased retinal vessel tortuosity and a darker aspect of the right eye with respect to the left eye, suggesting diffuse choroidal haemangioma (Fig. 3). B-scan ultrasound scans were performed and showed a marked difference in thickness and reflectance between the right and left choroid; manual double-check measurements of choroidal thickness were 2.2 and 1.4 $\mathrm{mm}$ for the right and left eye, respectively (Fig. 4a, b). Macular spectral domain OCT revealed a thicker choroid in the right eye with respect to the left eye (Fig. 5). Visual field examinations with perimetry showed early defects in the right eye. Peripapillary OCT imaging showed borderline values for retinal nerve fibre layer thickness in the right eye. Topical 
therapy with latanoprost was initiated in the right eye and intraocular pressure was reduced to $17 \mathrm{~mm} \mathrm{Hg}$.

\section{Discussion}

In this paper we present an unusual case of SWS with bilateral naevus flammeus and ocular melanocytosis of the right iris, together with the presence of ipsilateral iris mammillations, glaucoma, and diffuse choroidal haemangioma. The aetiopathogenetic mechanisms behind the vascular malformations of SWS have long been a matter of debate. However, Shirley et al. [19] recently identified a mutation in the GNAO gene which stimulates the proliferation of cells and inhibits apoptosis by a surge in downstream signalling through the RAS effector pathways and accounts for the angiomatosis in SWS. On the other hand, the pigmentation in oculodermal melanocytosis has been reported to be linked to an anomalous migration of melanocytes, which are derived from the neural crest cells; this maldevelopment is thought to be the cause of the pigmentation of various ocular structures [20]. The coexistence of oculodermal melanocytosis and naevus flammeus is a rare condition and seems to be related to a twin spotting mechanism that occurs with an association of 2 genetically different cell clones due to somatic type recombination [21]. The vascular involvement in the SWS, historically hypothesized to be due to a malformation of the primordial vascular plexus, has also been described in association with neural crest disorders and phacomatosis, where these mesodermal abnormalities are associated with neural crest disorders such as in oculodermal melanocytosis [22-24].

The clinical management of glaucoma in SWS can be extremely challenging and requires careful diagnostic work-up. Clinical procedures should include complete ophthalmological examination, intraocular pressure measurement, and gonioscopy where possible. Ultrasound biomicroscopy and anterior segment OCT can greatly facilitate in establishing anterior segment anomalies including angle alterations $[25,26]$. Visual field examination using perimetry is fundamental in the follow-up of patients who are able to cooperate. However, peripapillary retinal nerve fibre layer evaluation using OCT is a recent imaging method useful in young children as it is a more rapid procedure in order to screen for early damage [27, 28]. Fundus examination through ophthalmoscopy and fundus photography is crucial in screening for diffuse choroidal haemangioma, but OCT and B-scan ultrasound imaging can provide more precise data on the extent of choroidal thickening.

The pathogenetic mechanism of glaucoma in SWS can be due to a reduction of aqueous humour outflow due to a malformation of the anterior chamber angle or increased pressure in the episcleral veins [29-31]. In the case reported herein, SWS was also associated with ocular melanocytosis, where angle abnormalities or crowding of the iris-corneal angle by melanocytes have been reported to increase intraocular pressure similar to a mechanism in pigmentary or pseudoexfoliative glaucoma [32-34]. Anterior segment OCT did not show structural anomalies of the iris-corneal angle; therefore, treatment with latanoprost was prescribed to the patient as this drug increases uveoscleral outflow by bypassing the impediment to aqueous humour outflow due to increased episcleral venous pressure. Medical treatment of glaucoma in SWS, further complicated by ocular melanocytosis in this case, can be difficult and challenging, and potential side effects of this treatment can be uveal effusion, a condition also associated with antiepilepsy drugs such as topiramate $[35,36]$. When medical therapy is not successful, a surgical approach of goniotomy or trabeculotomy has been reported in cases with malformation of the angle. Filtering procedures such as trabeculec- 


\section{Case Reports in Ophthalmology}

tomy or valve implant procedures have been successful in the absence of angle anomalies, although complications are not infrequent [31].

The patient described in this paper presented iris mammillations, a condition seldom reported in the literature. These are homogeneously elevated micronodular, pigmented formations regularly distributed over the iris surface [14, 15, 32]. Differential diagnosis is principally with Lisch nodules of the iris, which occur in neurofibromatosis type 1 [37]. However, the nodules in neurofibromatosis tend to be larger and randomly located on the iris surface, and a differential diagnosis can also be made by performing near-infrared reflectance imaging as $82-90 \%$ of patients with neurofibromatosis present typical choroidal alterations [38, 39]. Other conditions which can mimic iris mammillations and should be kept in mind are tapioca melanoma of the iris, iris granulomata in inflammation, and the Cogan-Reese syndrome [14].

The patient reported herein presented a monolateral diffuse choroidal haemangioma, and B-scan ultrasonography showed thickening of the choroid of the right eye. Recent advances in OCT technology enable the visualization of the choroid, and its thickness can be measured in numerous retinal pathologies and in rare diseases including SWS [40-43]. In the case reported herein, OCT was carried out although the choroid was markedly thickened, and segmentation measurement of thickness was not reliable as the choroid-scleral junction could not be well defined. The choroidal haemangioma was asymptomatic in the present case; however, complications can potentially arise later in life. These are mainly serous retinal detachment and subretinal haemorrhage, which can lead to grave loss of vision [2]. Treatment in these cases is usually directed to reducing haemangioma leakage and possibly reducing tumour size. Among methods such as radiotherapy and photocoagulation, recent management options include photodynamic therapy and pharmacological treatment with intravitreal antivascular growth factors [31, 44-47]. Routine follow-up with fundus examination and multimodal imaging techniques including OCT and B-scan ultrasonography are fundamental as patients with oculodermal melanocytosis have been reported to be at increased risk for melanoma of the uvea [48].

\section{Conclusions}

We have described a rare case of SWS associated with bilateral naevus flammeus and monolateral ocular melanocytosis associated with ipsilateral iris mammillations and choroidal haemangioma. Diagnosis and evaluation of glaucoma and choroidal haemangioma in these patients can be facilitated with multimodal imaging techniques. Indeed, anterior segment OCT and ultrasound biomicroscopy enable the evaluation of the chamber angle in order to prescribe the most appropriate medication. Furthermore, posterior segment imaging such as macular OCT with assessment of the choroid, and peripapillary retinal nerve fibre layer evaluation using OCT, are additional diagnostic tools which have recently been added to the armamentarium of ophthalmologists and can further aid in the assessment of patients with rare diseases where our knowledge is still limited.

\section{Statement of Ethics}

Consent was given by the patient for the submission of the case report to the journal. 


\section{Case Reports in Ophthalmology}

Case Rep Ophthalmol 2017;8:375-384
\begin{tabular}{l|l}
\hline DOI: $10.1159 / 000477612$ & ○ 2017 The Author(s). Published by S. Karger AG, Basel
\end{tabular} www.karger.com/cop

Plateroti et al.: Sturge-Weber Syndrome Associated with Monolateral Ocular Melanocytosis, Iris Mammillations, and Diffuse Choroidal Haemangioma

Disclosure Statement

The authors declare that they have no conflicts of interest.

\section{References}

1 Sami D, Vivian A, Taylor D, Saunders D: The phakomatoses; in Tasman W, Jaeger EA (eds): Duane's Ophthalmology. 2006, vol 5, chapt 36.

2 Abdolrahimzadeh S, Scavella V, Felli L, Cruciani F, Contestabile MT, Recupero SM: Ophthalmic alterations in the Sturge-Weber syndrome, Klippel-Trenaunay syndrome and the phakomatosis pigmentovascularis: an independent group of conditions? Biomed Res Int 2015;2015:786519.

-3 Roach ES: Neurocutaneous diseases. Pediatr Clin North Am 1992;39:591-620.

$\checkmark 4$ Sujansky E, Conradi S: Sturge-Weber syndrome: age of onset of seizures and glaucoma and the prognosis for affected children. J Child Neurol 1995;10:49.

5 Sullivan TJ, Clarke MP, Morin JD: The ocular manifestations of the Sturge-Weber syndrome. J Pediatr Ophthalmol Strabismus 1992;29:349.

-6 Van Emelen C, Goethals M, Drelands L, Casteels I: Treatment of glaucoma in children with Sturge-Weber syndrome. J Pediatr Ophthalmol Strabismus 2000;37:29-34.

-7 Arora KS, Quigley HA, Comi AM, Miller RB, Jampel HD: Increased choroidal thickness in patients with Sturge-Weber syndrome. JAMA Ophthalmol 2013;131:1216-1219.

-8 Shechtman D, Vollmer L, Sowka J: Ocular vascular hamartomas: the relationship with phakomatoses and possible commonalities in pathogenesis. Optometry 2006;77:609-621.

-9 Recupero SM, Abdolrahimzadeh S, De Dominicis M, Mollo R: Sturge-Weber syndrome associated with naevus of Ota. Eye 1998;12:212-213.

10 Tran HV, Zografos L: Primary choroidal melanoma in phakomatosis pigmentovascolaris IIa. Ophthalmology 2005;112:1232-1235.

11 Teekhasaenee C, Ritch R, Rutmin U, Leelawongs N: Ocular findings in oculodermal melanocytosis. Arch Ophthalmol 1990;108:1114-1120.

12 Swann PG, Kwong E: The naevus of Ota. Clin Exp Optom 2010;93:4:264-267.

13 Chan HHL, Kono T: Nevus of Ota: clinical aspect and management. Skin Med 2003;2:89-97.

14 Ragge NK, Acheson J, Murphree AL: Irisi mammillations: significance associations. Eye 1996;10:86-91.

-15 Joondeph BC, Goldberg MF: Familiar melanosis: a misnomer? Br J Ophthalmol 1989;73:289-293.

16 Ota M, Kawamura T, Ito N: Phakomatosis pigmentovascularis (Ota). Jpn J Dermatol 1947;52:1-3.

-17 Recupero SM, Abdolrahimzadeh S, De Dominicis M, Mollo R: Sturge-Weber syndrome associated with nevus of Ota. Eye 1998;12:212-213.

-18 Scuderi GL, Cascone NC, Regine F, Perdicchi A, Cerulli A, Recupero SM: Validity and limits of the rebound tonometer (ICare®): clinical study. Eur J Ophthalmol 2011;21:251-257.

19 Shirley MD, Tang H, Gallione CJ, Baugher JD, Frelin LP, Cohen B, North PE, Marchuk DA, Comi AM, Pevsner J: Sturge-Weber syndrome and port wine stains caused by somatic mutation in GNAQ. N Engl J Med 2013;368:1971-1979.

20 Teekhasaenee C, Ritch R, Rutnin U, Leelawongs L: Ocular findings in oculodermal melanocytosis. Arch Ophthalmol 1990;108:1114-1120.

-21 Shields CL, Kligman BE, Suriano M, Viloria V, Iturralde JC, Shields MV, Say EA, Shields JA: Phacomatosis pigmentovascularis of cesioflammea type in 7 patients. Arch Ophthalmol 2011;129:746-750.

22 Villaverde RR, Ramirez AV, Solano L, Sintes RN, Salmeron MT: Phakomatosis pigmentovascularis and Lisch nodules. Relationship between Von Recklinghausen and phakomatosis pigmentovascularis? J Eur Acad Dermatol Venereol 2003;17:53-55.

23 Van Gysel D, Oranje AP, Stroink H, Simonsz HJ: Phakomatosis pigmentovascularis. Pediatr Dermatol 1996;13:33-35.

-24 Abdolrahimzadeh S, Felli L, Piraino DC, Mollo R, Calvieri S, Recupero SM: Retinal microvascular abnormalities overlying choroidal nodules in neurofibromatosis type 1. BMC Ophthalmol 2014;14:146.

-25 Nolan W: Anterior segment imaging: ultrasound biomicroscopy and anterior segment optical coherence tomography. Curr Opin Ophthalmol 2008;19:115-121.

26 Mannino G, Malagola R, Abdolrahimzadeh S, Villani GM, Recupero SM: Ultrasound biomicroscopy of degenerative retinoschisis and allied alterations of the ciliary body. Br J Ophthalmol 2001;85:976-982.

-27 Avery RA, Cnaan A, Schuman JS, Chen CL, Glaug NC, Packer RJ, Quinn GE, Ishikawa H: Intra-and intervisit reproducibility of ganglion cell-inner plexiform layer measurements using handheld optical coherence tomography in children with optic pathway gliomas. Am J Ophthalmol 2014;158:916-923. 
Abdolrahimzadeh S, Felli L, Plateroti AM, Perdicchi A, Contestabile MT, Recupero SM: Spectral domain optical coherence tomography evidence of retinal nerve fibre layer and ganglion cell loss in adult patients with neurofibromatosis type 1. Retina 2016;36:75-81.

29 Weiss DI: Dual origin of glaucoma in encephalotrigeminal haemangiomatosis. Trans Ophthalmol Soc UK 1973;93:477.

30 Phelps CD: The pathogenesis of glaucoma in Sturge-Weber syndrome. Ophthalmology 1978;85:276286.

-31 Abdolrahimzadeh S, Fameli V, Mollo R, Contestabile MT, Perdicchi A, Recupero SM: Rare diseases leading to childhood glaucoma: epidemiology, pathophysiogenesis and management. Biomed Res Int 2015;2015:781294.

Plateroti AM, Scavella V, Abdolrahimzadeh B, Plateroti R, Rahimi S: An Update on oculodermal melanocytosis and rare associated conditions. Semin Ophthalmol 2016;15:1-5.

-33 Magarasevic L, Abazi Z: Unilateral open angle glaucoma associated with the ipsilateral nevus of Ota. Case Rep Ophthalmol Med 2013;2013:924937.

-34 Plateroti P, Plateroti AM, Abdolrahimzadeh S, Scuderi GL: Pseudoexfoliation syndrome and pseudoexfoliation glaucoma: a review of the literature with updates on surgical management. J Ophthalmol 2015;2015:370371.

35 Maruyama I, Ohguro H, Nakazawa M: A case of acute angle-closure glaucoma secondary to posterior scleritis in patient with Sturge-Weber syndrome. Jpn J Ophthalmol 2002;46:74-77.

36 Cruciani F, Lorenzatti M, Nazzarro V, Abdolrahimzadeh S: Bilateral acute angle closure glaucoma and myopia induced by topiramate. Clin Ter 2009;160:215-216.

37 Recupero SM, Plateroti R, Abdolrahimzadeh S, De Dominicis M, Giustini S, Noviello MR, Calvieri S: Lisch nodules in neurofibromatosis type 1 . Relationship to age and cutaneous neurofibromas. Ann Ophthalmol 1996;28:178-183.

-38 Viola F, Villani E, Natacci F, Selicorni A, Melloni G, Vezzola D, Barteselli G, Mapelli C, Pirondini C, Ratiglia R: Choroidal abnormalities detected by near-infrared reflectance imaging as a new diagnostic criterion for neurofibromatosis 1. Ophthalmology 2012;119:369-375.

39 Abdolrahimzadeh S, Felli L, Plateroti R, Plateroti AM, Giustini S, Calvieri S, Recupero SM: Morphological and vascular features of the choroid and associated choroid-retinal thickness alterations in neurofibromatosis type 1 . Br J Ophthalmol 2015;99:789-793.

40 Spaide RF, Koizumi H, Pozonni MC: Enhanced depth imaging spectral-domain optical coherence tomography. Am J Ophthalmol 2008;146:492-500.

41 Abdolrahimzadeh S, Parisi F, Scavella V, Recupero SM: Optical coherence tomography evidence on the correlation of choroidal thickness and age with vascularized retinal layers in normal eyes. Retina 2016;36:2329-2338.

-42 Arora KS, Quigley HA, Comi AM, Miller RB, Jampel HD: Increased choroidal thickness in patients with Sturge-Weber syndrome. JAMA Ophthalmol 2013;131:1216-1219.

-43 Abdolrahimzadeh S, Scavella V, Battaglia D, Recupero SM: Spectral domain optical coherence tomography of choroidal and outer retinal layer thickness in the Sturge-Weber syndrome. Curr Eye Res 2016;41:1614-1617.

44 Zografos L, Bercher L, Chamot L, Gailloud C, Raimondi S, Egger E: Cobalt-60 treatment of choroidal hemangiomas. Am J Ophthalmol 1996;121:190-199.

-45 Paulus YM, Jain A, Moshfeghi DM: Resolution of persistent exudative retinal detachment in a case of Sturge-Weber syndrome with anti-VEGF administration. Ocul Immunol Inflamm 2009;17:292-294.

-46 Fenicia V, Abdolrahimzadeh S, Mannino G, Verrilli S, Balestrieri M, Recupero SM: Intravitreal bevacizumab in the successful management of choroidal metastases secondary to lung and breast cancer unresponsive to systemic therapy: a case series. Eye (Lond) 2014;28:888-891.

47 Cerman E, Cekij 0: Clinical use of photodynamic therapy in ocular tumors. Surv Ophthalmol 2015;60:557-574.

48 Singh AD, DePotter P, Fijal BA: Life time prevalence for uveal melanoma in white patients with oculo(dermal) melanocytosis. Ophthalmology 1998;105:195-198. 
Case Reports in
Ophthalmology Case Rep Ophthalmol 2017;8:375-384 DOI: $10.1159 / 000477612$

C 2017 The Author(s). Published by S. Karger AG, Basel www.karger.com/cop

Plateroti et al:: Sturge-Weber Syndrome Associated with Monolateral Ocular Melanocytosis, Iris Mammillations, and Diffuse Choroidal Haemangioma
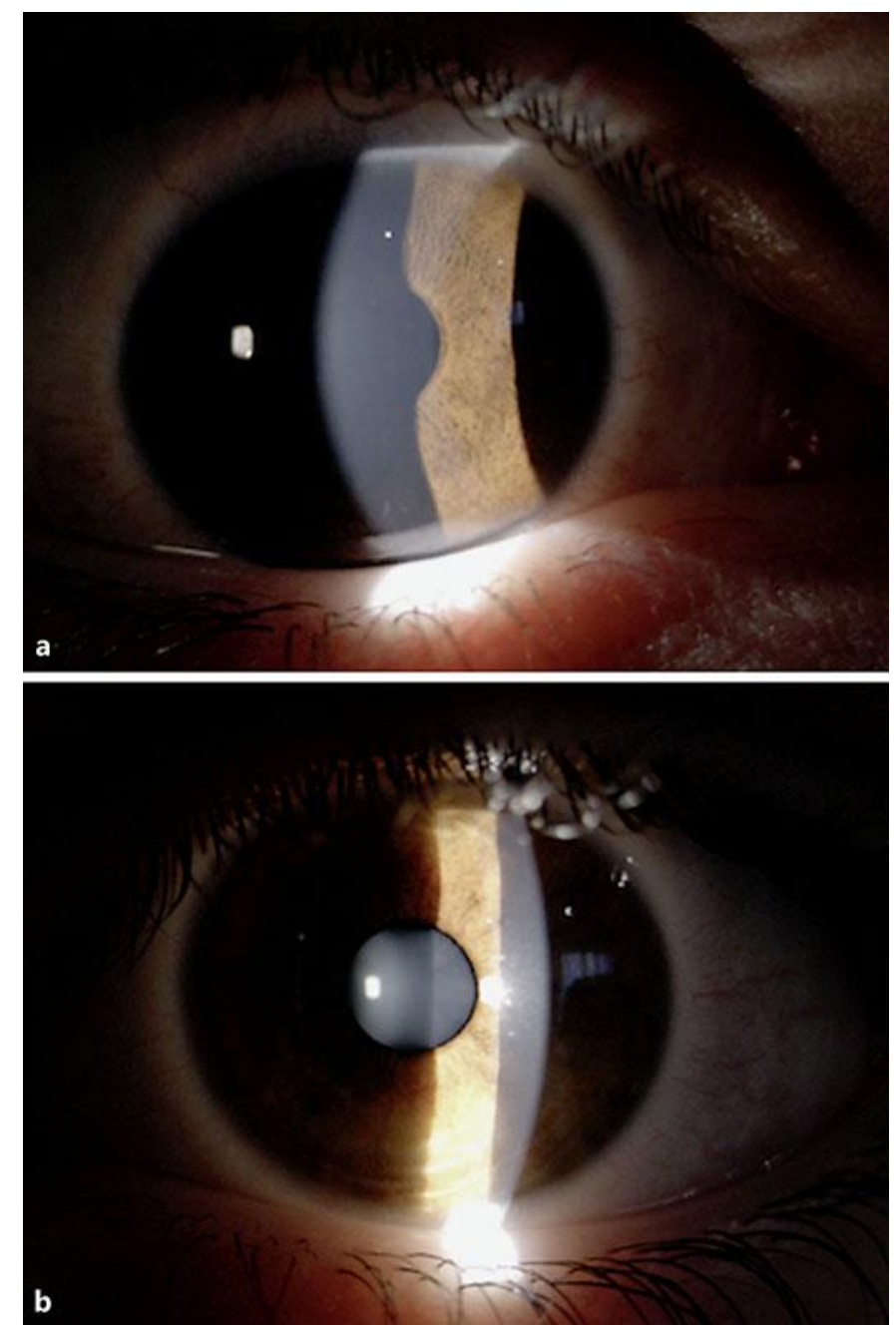

Fig. 1. Slit lamp images of the anterior segment in the right (a) and left (b) eye. Slit lamp examination showed iris heterochromia due to hyperpigmentation of the right iris associated with ipsilateral iris mammillations.. 


\section{Case Reports in Ophthalmology}

\begin{tabular}{l|l}
\hline Case Rep Ophthalmol 2017;8:375-384 \\
\hline DOI: 10.1159/000477612 & $\begin{array}{l}\text { C 2017 The Author(s). Published by S. Karger AG, Basel } \\
\text { www.karger.com/cop }\end{array}$ \\
\hline
\end{tabular}

Plateroti et al: Sturge-Weber Syndrome Associated with Monolateral Ocular Melanocytosis, Iris Mammillations, and Diffuse Choroidal Haemangioma

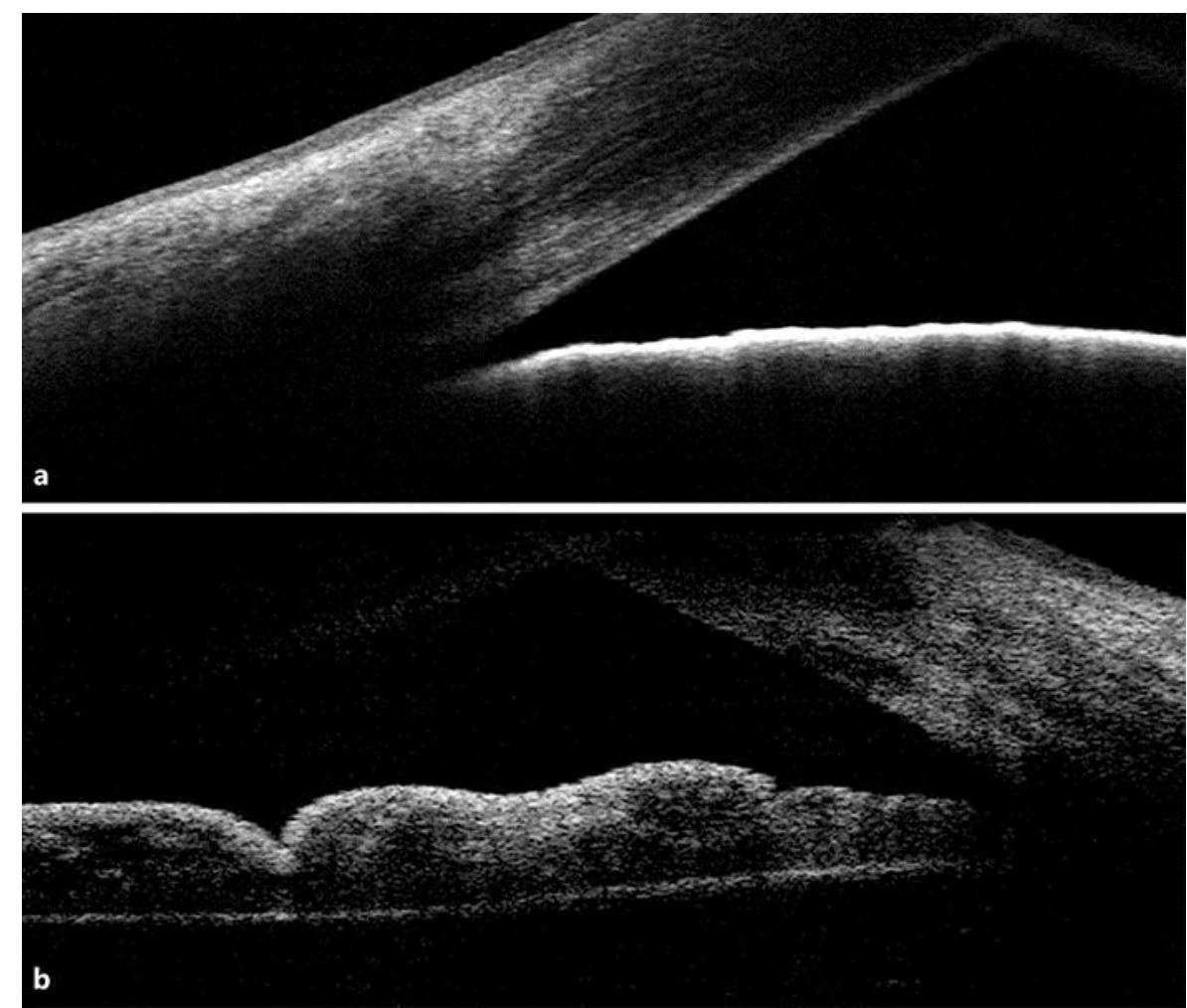

Fig. 2. Anterior segment optical coherence tomography of the right (a) and left (b) eye. There is an evident increase in reflectance of the iris surface in the right eye (a).
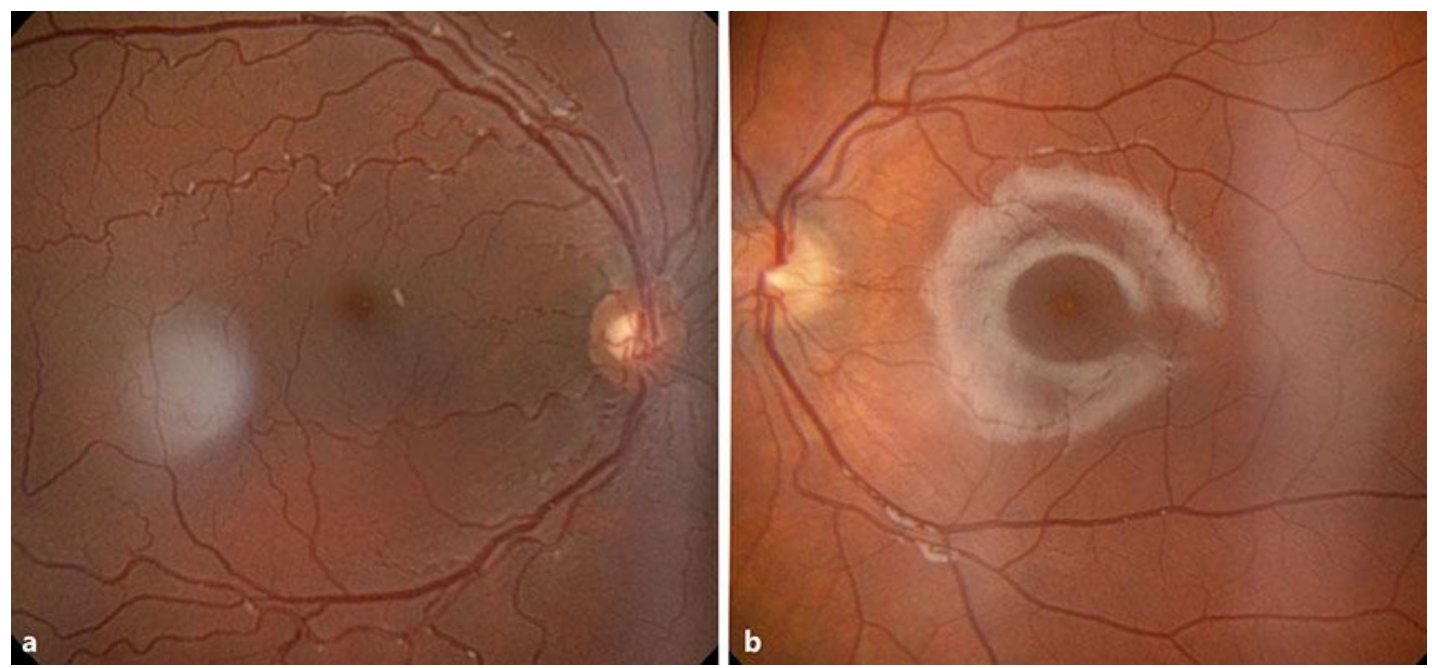

Fig. 3. Right (a) and left (b) eye fundus images. The colour of the right fundus is darker due to diffuse choroidal haemangioma where there is increased tortuosity of the retinal vessels. 


\section{Case Reports in Ophthalmology} www.karger.com/cop

Plateroti et al: Sturge-Weber Syndrome Associated with Monolateral Ocular Melanocytosis, Iris Mammillations, and Diffuse Choroidal Haemangioma

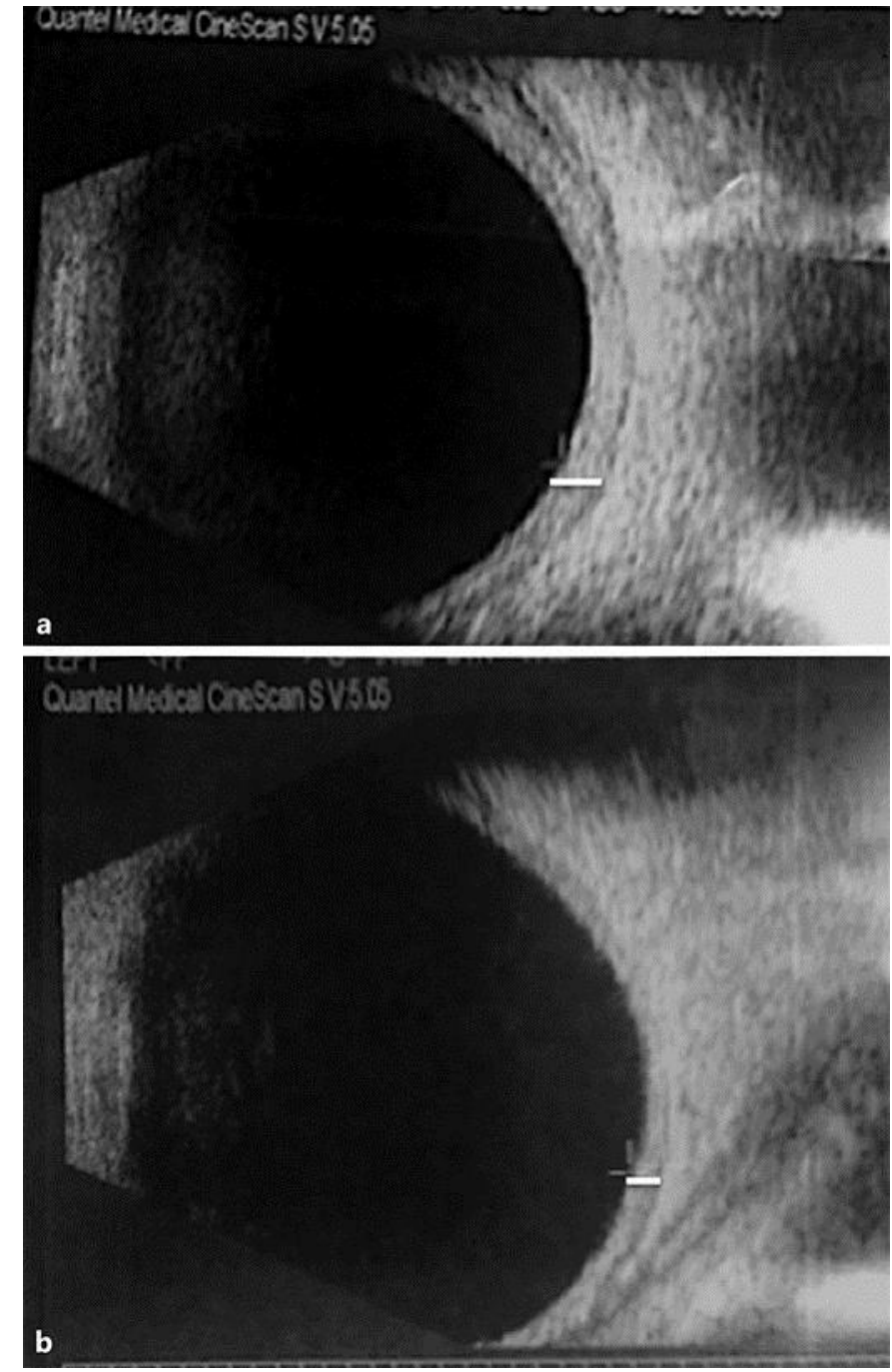

Fig. 4. Ultrasound scans of the right (a) and the left (b) eye. Increased thickness of the choroid is shown in the right eye (choroidal thickness of 2.2 and $1.4 \mathrm{~mm}$ for the right and left eye, respectively). Lines indicate choroidal thickness. 


\section{Case Reports in Ophthalmology}

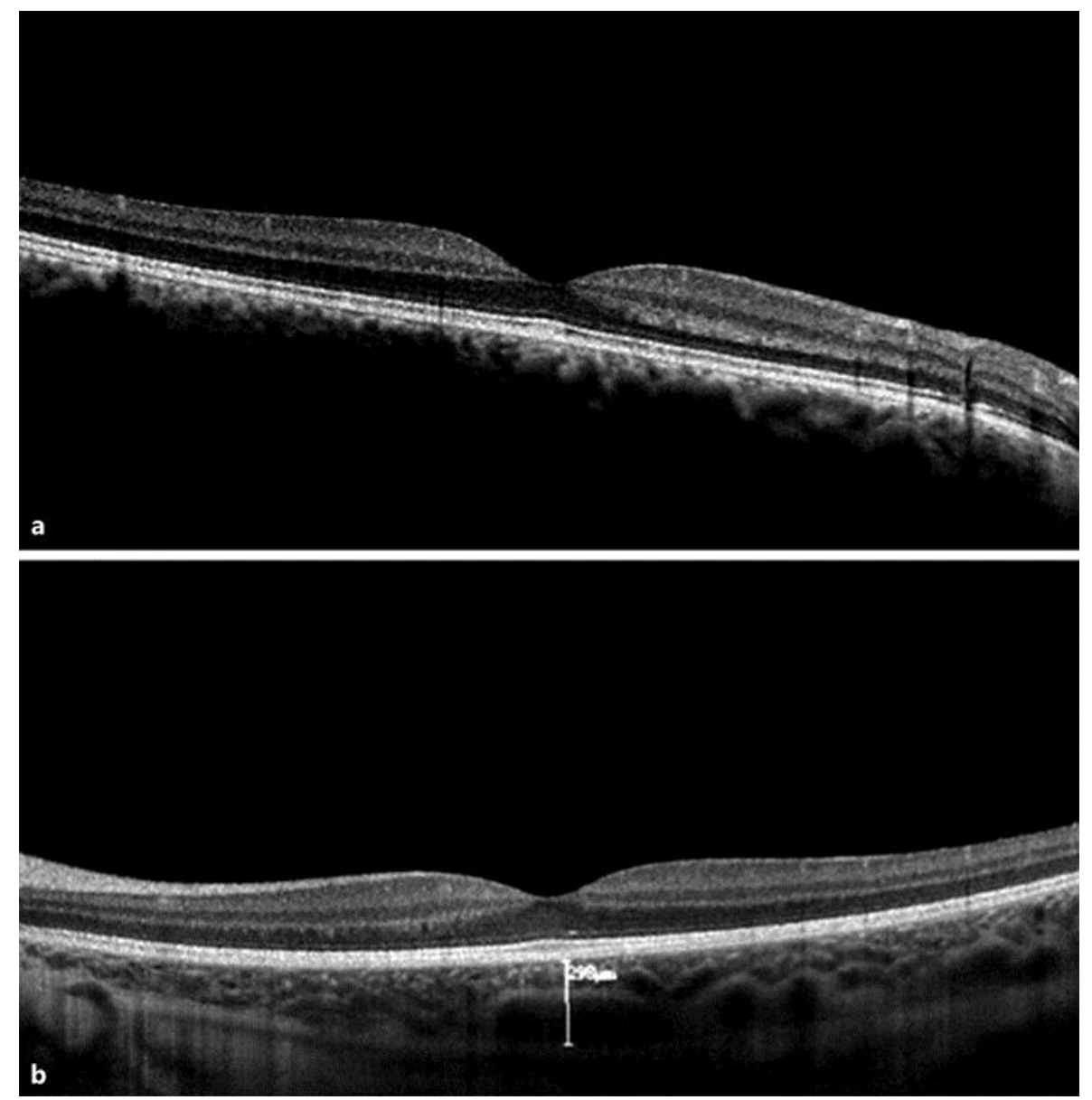

Fig. 5. Macular optical coherence tomography of the right (a) and left eye (b). In the right eye choroidal thickness could not be measured as the choroid-scleral border could not be evaluated due to increased choroidal thickness. 